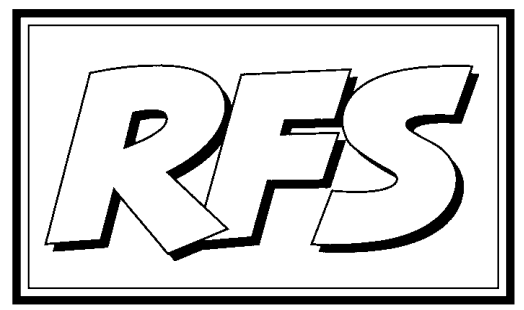

Revista de Fomento Social, 53 (1998), 295-310

\title{
RECENSIONES
}

SOCIOLOGÍA

Groupe De Lisbonne (1995), Limites à la compétitivité. Pour un niveau contrat mondial. Sous la direction de RicCARDO Petrella, Ed. Labor, Bruxelles, 230 págs.

En estos últimos años está proliferando el género «informe» para abordar los grandes temas de nuestro mundo. El ser trabajos, no de un solo autor, sino de un equipo puede ser simplemente reflejo de la complejidad de los problemas mismos. Y la frecuencia con que ahora aparecen estudios de este estilo puede contribuir a que comiencen a ser menos apreciados.

Valgan estas consideraciones iniciales para llamar la atención sobre este informe del Grupo de Lisboa, que ha aparecido ya en diez idiomas (la versión castellana ha sido publicada en Buenos Aires). El grupo -formado por 19 personas procedentes de la Tríada (Japón, Europa occidental y América del Norte)-comenzó sus trabajos en 1992, quinto aniversario del descubrimiento del Nuevo Mundo. Se escogió Lisboa por ser ciudad emblemática, de la que partieron muchos conquistadores: pero quienes ahora se reúnen aquí van a proponer un nuevo orden mundial que repose en la cooperación y no en las conquistas. Riccardo Petrella, el impulsor del grupo y el redactor del informe, es director del Programa FAST (Forecasting and Assesment in Science and Technology) en la Comisión de la Unión Europea.

La cuestión central que este libro plantea es: ¿pueden la competencia y la competitividad regir el planeta y constituir el instrumento por excelencia para resolver los problemas de orden medioambiental, demográfico, económico y social, que asaltan a la tierra entera? Y la conclusión final es terminante: «el imperativo de la competencia económica es incapaz de gobernar solo el planeta; (...) la lógica de la conquista-de los mercados y del poder 
económico y financiero- con vistas a dominar el mundo constituye una visión superada e irrealista de las cosas» (pág. 221). A esta constatación de un camino sin salida se contrapone una alternativa que los autores creen viable: orientarse hacia una forma de gobierno que repose sobre la cooperación y la cohabitación. Una propuesta así puede resultar de entrada utópica. Y no es que el informe resuelva todos los interrogantes que se suscitan, pero sí ofrece algunas pistas que constituyen lo más valioso de su aportación.

\section{Competitividady mundialización}

El tema de la competitividad es clave en el informe, como se deduce del título mismo con que ha sido publicado. Y la toma de posición de los autores frente a ella es muy crítica. No es que rechacen la competencia en cuanto tal, pero sí los excesos de la ideología de la competencia cuando ésta pretende sustituir a otras formas de organización de la vida económica, política y social. Denuncian que la competitividad se ha erigido en el único valor hasta el punto de que la lógica del mercado competitivo ha terminado imponiéndose a todas las esferas de la vida individual y colectiva (educación, comportamiento en la familia, desarrollo de la colectividad, funcionamiento de las instituciones democráticas).

La mundialización a todos los niveles ha acentuado este proceso: la competitividad ha pasado de medio a fin, convirtiéndose en un objetivo ofensivo para asegurar la supervivencia y la hegemonía. El principio de que «hay que vencer a cualquier precio», que ha marcado la economía mundial, está configurando nuestro planeta a todos los niveles. Sin negar los aspectos positivos de dicha mundialización, tampoco pueden ignorar que ella tiene no poco que ver con los grandes problemas nuevos y con la multiplicación de nuevos retos sociales: medio ambiente, explosión demográfica, desempleo generalizado, inmigración masiva, crimen organizado, tráfico de drogas, conflictos étnicos y religiosos, nuevas epidemias (SIDA) y reaparición de otras antiguas (malaria y peste). La rapidez con que la economía de los mercados financieros y de las empresas se mundializa corre pareja con la naturaleza explosiva de la mayoría de estos problemas.

\section{Mirando al pasado: el capitalismo y el Estado-nación}

El informe tiene siempre como referente implícito $-\mathrm{y}$ muchas veces explícito también-lahistoria del capitalismoliberal y su paso al capitalismo mixto. En el siglo XIX los excesos del capitalismo naciente tuvieron que ser contrapesados con leyes antitrust, leyes para la protección de los trabajadores, programas de protección social contra la exclusión, etc. Gracias a todo eso fue surgiendo un contrato social nacional, gracias al cual el Estado se erige en promotor y garante de los intereses de la población frenando los impulsos del capitalismo competitivo nacional.

Hoy la fuente de los problemas es la 
misma, sólo que el capitalismo actúa ahora a escala mundial. Y no sólo no hay una instancia equivalente que le sirva de contrapeso (¡nadie piensa en una especie de «Estado mundial»!), sino que la creciente mundialización incluso limita las posibilidades de actuación que habían legitimado al Estado en el siglo XX.

Esta mirada a la historia del capitalismo, y a la superación del modelo liberal, refuerza la convicción de que el mercado no podrá garantizar la convivencia planetaria por mucho que se ponderen las virtudes de la mundialización.

\section{Economía mundializada, sociedad mundializada}

El mundo global es el resultado de una reorganización profunda que afecta al primer mundo, al segundo y al tercero, hasta dar una nueva configuración al planeta. Para mostrar el alcance de este proceso los autores hacen una clara distinción entre internacionalización y multinacionalización, a las que consideran dos fenómenos que cuentan con una larga historia, y mundialización propiamente dicha.

Lo que caracteriza a la mundialización es que la historia ha dejado de estructurarse por dinámicas de carácter nacional. Con la mundialización de la economía -cuyos motores son la liberalización, la privatización y la desregulación-cae una de las bases principales del Estado-nación, el mercado nacional: ahora, el espacio económico por excelencia desde el punto de vista estratégico es el espacio mundial. Pero además el Estado nacional ha dejado de ser la forma última de organización política y social. Tampoco la identidad nacional determina ya la existencia y la personalidad de los individuos y de los grupos sociales. Y ni siquiera la historia nacional (lengua, cultura, sistema educativo, red ferroviaria, equipos deportivos) es capaz de constituir ya el núcleo en torno al que la sociedad se construye.

No es que el Estado nacional haya desaparecido. Tampoco desaparecerá a corto plazo. Pero ya no puede pretender jugar el papel hegemónico de otros tiempos, que le permitía intervenir incluso en el gobierno de los asuntos mundiales.

Pero este nuevo contexto mundial supone también la emergencia de una sociedad civil mundial, formada por grupos sociales e instituciones organizadas que actúan a escala local, nacional y planetaria en las más diversas esferas de la actividad humana. Es como una nebulosa donde se entremezclan los grupos más variopintos tanto por sus preocupaciones dominantes, como por sus orientaciones ideológicas como por el grado de militancia de sus miembros. Conjunto tan variado y heterogéneo juega un papel histórico importante, cuyas funciones son difíciles de exagerar: se convierte poco a poco en la conciencia mundial del planeta (haciéndose portavoz universal de lo bueno, de lo bello, de lo justo, de lo maravilloso, de la fraternidad y de la tolerancia); de ese modo expresa y elabora las necesidades, aspiraciones y objetivos mundiales, que se conforman así como una verdadera demanda social mundial. 


\section{Hacia un gobierno mundial eficaz}

En opinión de muchos la competitividad puede gobernar el mundo, ya que ella bastaría para solucionar los grandes problemas del planeta. Esta tesis se pretende justificar con algunas pocas ideas, muy sencillas, que se presentan como inevitables. Por ejemplo: en esa guerra técnica, industrial y económica, en que vivimos inmersos, es preciso ser fuertes para vencer; no hay opción, porque los otros ya han hecho la suya de ser nuestros oponentes; en esa guerra tiene que haber un ganador; a mayor competitividad, mayores son las posibilidades de sobrevivir, mientras que la carencia de competitividad significa la exclusión del mercado, la pérdida del control sobre el futuro y el sometimiento al más fuerte.

Pero hay que ser muy críticos ante esta exaltación tan desmedida de la competitividad y denunciar sus limitaciones. En lo económico reduce los seres humanos a meros productores y consumidores, da prioridad a los costes financieros a corto plazo, refuerza las disparidades en el seno de un país y entre los países (el mundo «integrado» frente al mundo de los «excluidos»). Y, más allá de lo económico, crea una cultura que estimula la combatividad individual y colectiva e impide la solidaridad y el diálogo entre las personas, las naciones y las colectividades. Más aún, reduce los medios de intervención de las autoridades públicas y de la democracia representativa, a escala local, nacional y mundial.

¿A quién entonces confiar el gobierno mundial, si no es posible hacerlo a la competitividad? La propuesta del Grupo de Lisboa se inspira en las teorías del contrato social, que está a la base del Estado moderno, y se concreta en algunos contratos a escala mundial, muy sectoriales quizás, pero capaces de abrir un nuevo camino. La sociedad civil mundial, ya mencionada, servirá de sustento e impulso para este proceso. Pero un contrato de este tipo no podría prescindir de la realidad que nos circunda: por eso tendría que integrar las energías que se articulan en torno al Estado-nación y al capitalismo librecambista. Ese es el gran reto de la hora presente. De algún modo es lo que pretenden los proyectos de integración regional. Pero hay que ir más allá hasta llegar a un conjunto de procedimientos e instituciones de alcance mundial.

Un contrato no es más que una opción de carácter colectivo: las partes en presencia, cuyos intereses son, en principio, divergentes, deciden fijarse objetivos comunes una vez que han constatado que es más beneficioso marchar todos en la misma dirección que hacerlo en direcciones opuestas. Un acuerdo de este tipo facilitaría el tránsito hacia un sistema mundial de gobierno y de regulación de los asuntos planterios, un sistema que se iría configurando como un conjunto de reglas, mecanismos e instituciones de «gobierno» directo o representativo del que todas las partes interesadas se beneficiarían.

Los contratos que el informe propone para empezar a caminar por esta nueva vía se refieren a cuatro áreas específicas: un 
contrato de las necesidades fundamentales, cuyo objetivo sea lucha contra las desigualdades enjugando las miserias de las poblaciones más pobres (debería concretarse al suministro de agua, de vivienda y de energía respetuosa del medio ambiente); un contrato cultural, orientado a promover y apoyar las políticas y campañas que favorezcan la tolerancia y el diálogo entre las culturas; un contrato de la democracia, que se propusiera constituir algunas instituciones de carácter representativo (como podría ser una asamblea mundial de los ciudadanos); un contrato de la tierra, con el fin de avanzar en la línea de los compromisos asumidos por 130 gobiernos en la Cumbre de Río.

\section{Una valoraciónfinal}

A medida que se avanza en la lectura de este libro y se pasa del análisis a las propuestas, uno tiene la impresión de irse sumergiendo en un mundo cada vez más idealizado. Pero el rigor con que se lleva a cabo el análisis es un estímulo para no claudicar en la búsqueda de soluciones.

El punto crucial es el análisis de la competitividad y la función que hoy desempeña en el mundo. Si ella nos parece el mejor camino o, más simplemente, un destino inevitable, no tiene ya sentido seguir leyendo. Pero si no nos resignamos a pensar que no hay alternativas, la lectura del libro nos cautivará.

En la búsqueda de soluciones el Grupo de Lisboa abre dos caminos. El primero es la historia: reflexionar sobre por qué y cómo el capitalismo liberal pasó a capitalismo mixto y provocó una profunda trans- formación del Estado. El segundo es la atención a los nuevos dinamismos que comienzan a aparecer a escala planetaria como reacción contra la competitividad dominante: la emergencia de una sociedad civil mundial, sus posibilidades y limitaciones, es lo que mejor sintetiza estos nuevos dinamismos; pero en esa línea hay que situar también los movimientos, ya reales, que favorecen esos cuatro contratos mundiales que el informe sugiere.

Sobre estas bases se entreabren perspectivas. Cómo avanzar es la cuestión en la que el informe no entra. $Y$ lo reconoce modestamente. Pero su contribución no es despreciable si invita a pensar, estimula a ser creativos y favorece un no disimulado inconformismo, que tanto choca con el talante que hoy se impone en nuestro mundo.

Ildefonso Camacho Laraña S.J.

\section{EDUCACIÓN}

CONTRERAS DOMINGO, J. (1997), La autonomía del profesorado, Ed. Morata, Madrid, 232 págs.

Bajo un título, que sugiere otro contenido, la obra de J. Contreras es una reflexión sobre los diversos aspectos que rodean a la profesión de enseñar. Contreras vincula la manera de ejercer la profesión de la enseñanza con la forma de 